\title{
Purwarupa Pengoperasian TV Dengan Mendeteksi Isyarat Jari Berbasis Pengolahan Citra Digital
}

\author{
Handreas Okta Wibawa* ${ }^{1}$, Agus Harjoko ${ }^{2}$ \\ ${ }^{1}$ Program Studi Elektronika dan Instrumentasi; JIKE, FMIPA, UGM, Yogyakarta \\ ${ }^{2}$ Jurusan Ilmu Komputer dan Elektronika, FMIPA UGM, Yogyakarta \\ e-mail: *11yasrefah@gmail.com, ${ }^{2}$ aharjoko@ugm.ac.id
}

\begin{abstract}
Abstrak
Perkembangan teknologi komputer dan elektronika yang sangat pesat saat ini membuat manusia mulai mencari solusi lain untuk melakukan kegiatan menjadi lebih mudah dan praktis. Teknologi-teknologi yang berkembang dan dapat dimanfaatkan saat ini sangat memungkinkan manusia untuk memudahkan aktifitas dalam mengoperasikan TV dengan isyarat jari.

Dalam penelitian ini, pengolahan citra digital merupakan teknologi yang digunakan untuk mengoperasikan TV dengan memanfaatkan webcam dan komputer sebagai pengolah citra. Input dari penelitian ini berupa citra tangan hasil tangkapan webcam pada komputer. Kemudian citra tangan diolah melalui sistem pengolah citra untuk mendapatkan hasil berupa nilai pada jari tangan. Nilai tersebut menunjukkan angka yang sama dengan jumlah jari tangan yang terdeteksi oleh webcam pada layar monitor. Mikrokontroler berfungsi menerima data serial dari hasil pemrosesan citra tangan dan berfungsi sebagai konversi nilai data serial menjadi instruksi yang dapat mengoperasikan TV. Model warna yang dipakai adalah model $H S V$.

Langkah awal pengujian pada penelitian ini dilakukan dengan setting ruangan agar pengambilan citra mendapatkan hasil yang terbaik pada setiap ruangan. Hasil dari pengujian ini didapatkan nilai yang terbaik untuk pengoperasian TV dengan isyarat jari yaitu : untuk nilai intensitas cahaya sebesar 12 lux, nilai jarak terbaik sebesar $70 \mathrm{~cm}$ dan background terbaik berupa warna biru.
\end{abstract}

Kata kunci- TV, pengolahan citra, model warna HSV

\begin{abstract}
The development computer technology and electronics very rapidly at this time makes people start looking for other solutions to perform activities easier and more practical. Technologies are developed and can be used at this time it is possible to facilitate the activities human beings to operate TV with finger gesture.

In this research, digital image processing of technology can be used to operate TV using webcam and computer as image processing. Input this research is hand image that catched by webcam on computer. Then hand image processed through image processing system to obtain results form value fingers. This value indicates the number equal to number fingers detected by webcam camera on monitor screen. Microcontroller function is receives serial data from results image processing and serves serial data conversion value into instructions can operate TV. Color model used in research is HSV.

First step testing this research is setting room in order to capture image for get best results in any room. Results of the research found best value for testing operation TV with finger gesture is : for value light intensity is 12 lux, best distance is $70 \mathrm{~cm}$ and best baskground is blue.
\end{abstract}

Keywords - TV, image processing, HSV color model 


\section{PENDAHULUAN}

Ceiring dengan terus meningkatnya kemajuan teknologi komputer dan elektronika, peranan teknologi komputer dan elektronika dalam mendukung kepentingan manusia juga semakin meningkat. Perkembangan teknologi komputer dan elektronika menimbulkan kecenderungan untuk membuat kegiatan manusia menjadi lebih mudah dan praktis, salah satunya adalah pengendalian tanpa kabel. Pengendalian tanpa kabel ada beberapa macam, antara lain dengan menggunakan : gelombang radio, ultrasonik, dan cahaya infra merah, namun pada umumnya peralatan elektronik seperti : TV, sattelite receiver, video player, tape recorder, $\mathrm{CD}$ player, laser-disk player menggunakan pengalih cahaya infra merah pada pengendalinya. Peralatan elektronik seperti TV dilengkapi dengan pengendali tanpa kabel yaitu remote. Fungsi remote sangatlah penting bagi pengguna TV. Hal ini dikarenakan remote berfungsi sebagai pengendali jarak jauh bagi TV, antara lain: menghidupkan atau mematikan TV, merubah chanel TV, mengubah volume TV, dll. Selain itu fungsi remote juga menggantikan fungsi tombol manual yang ada pada TV untuk mengoperasiakan TV.

Pengguna TV umumnya merasakan tidak nyaman jika remote TV mengalami kerusakan sehingga mengakibatkan kesulitan dalam mengoperasikan TV. Tetapi hal ini juga bisa disiasati dengan mengopersikan TV dengan tombol manual yang terdapat pada TV. Dalam waktu yang singkat keadaan ini tidak menjadi masalah. Tetapi untuk jangka waktu yang lama akan membuat pengguna TV menjadi tidak nyaman dalam menonton TV.

Pada tahun 2009 Gunanto [1] mencoba melakukan segmentasi dengan menggunakan metode deteksi warna HSV untuk memisahkan citra bagian tubuh manusia yang diberi warna tertentu. Penelitian tersebut menggunakan data input berupa citra 2 dimensi dengan latar belakang homogen berwarna putih dan fitur model manusia. Model manusia menggunakan pakaian dengan warna tertentu pada tiap bagian tubuh manusia yang akan dikenali. Proses segmentasi warna dengan menggunakan deteksi warna HSV menghasilkan segmen warna yang akurat sesuai dengan warna sampel dan nilai toleransi yang diberikan. Hasil segmentasi warna tersebut menghasilkan segmen citra yang membentuk suatu blob, yaitu sekumpulan piksel bertetangga atau memiliki nilai tertentu.

Pada tahun 2009 Olivera [2] membuat sistem untuk memilah warna kulit manusia, bisa menggunakan metode konversi citra dari RGB ke HSV. Citra akan dipilah berdasarkan range warna yang dimiliki kulit manusia secara umum, baik hue, saturation, dan value-nya.

Pada tahun 2011 Ho [3] membuat sistem pengambilan gambar masukan citra pola jari tangan berupa video dengan webcam. Pengambilan citra dilakukan dengan menggunakan latar belakang berwarna hitam untuk memudahkan pemisahan citra tangan dengan latar belakangnya. Metode yang dipakai dalam memisahkan citra tangan dengan latar belakangya adalah ekualisasi histogram, kemudian dihaluskan dengan filter Gauss, lalu di-threshold untuk menguatkan nilai masing-masing pixel. Setelah objek tangan dipisah dari latar belakang, kemudian dicari kontur dari tangan. Kontur yang dihasilkan kemudian dihitung titik tengahnya, dari sana didapatkan koordinat titik tengah dari tangan. Penelitian tersebut tidak hanya mendeteksi tangan tapi juga mengenali arah/direction dari tangan. Dengan isyarat jari telunjuk, kontur tangan akan berubah, dari sana bisa dicari koordinat ujung jari telunjuk. Setelah itu koordinat ujung jari dan titik tengah dibandingkan dan dihitung jarak dan sudutnya.

Pada tahun 2012 Agarwal [4] membuat sistem pengambilan gambar seperti kamera dengan webcam hanya dengan membentuk isyarat „L" dengan telunjuk dan ibu jari. Segmentasi antara kulit dengan latar belakang memerlukan beberapa metode untuk menghilangkan derau. Metode yang digunakan antara lain adalah erotion dan dilation, yakni untuk mengurangi derau berukuran kecil juga mempertajam citra. Hal ini dilakukan sebelum mencari kontur dari tangan.

Pada tahun 2012 Hilmi [5] menggunakan webcam untuk menangkap citra, kemudian citra diolah sampai mengenali isyarat jari sehingga dapat mengendalikan dental light. Pengenalan isyarat jari menggunakan metode pemisahan objek dengan latar belakangnya.

IJEIS Vol. 5, No. 1, April 2015: $31-42$ 
Range warna dari sarung tangan dokter dipakai sebagai acuan pengenalan objek tangan. Model warna yang dipakai adalah model HSV.

\section{METODE PENELITIAN}

\subsection{Analisis Perancangan Sistem}

\subsubsection{Rancangan Sistem Secara Keseluruhan}

Sistem ini menggunakan webcam yang berfungsi menangkap citra tangan. Citra tangan akan dimanipulasi untuk mendapatkan jari tangan saja yang berfungsi sebagai isyarat pengoperasian TV. Jari tangan yang ditangkap oleh kamera webcam akan menunjukkan angka pada layar monitor sesuai dengan jumlah jari yang tertangkap kamera webcam, misalkan : satu jari, dua jari, tiga jari, empat jari atau lima jari tangan. Jumlah jari tersebut nantinya menunjukkan angka yaitu : 1,2, 3, 4 dan 5. Angka yang ditunjukkan dari hasil penangkapan jumlah jari oleh kamera webcam akan menjadi masukan untuk mengoperasikan TV.

Pemrosesan citra jumlah jari dilakukan melalui laptop dengan divais pengolah citra, di dalam program sistem deteksi jari tersebut terdapat 5 jenis output, yaitu angka 1, 2, 3, 4 dan 5 . Hasil yang berupa angka pada pengolahan citra kemudian dikirimkan hasilnya secara serial ke mikrokontroler. Pada mikrokontroler, nilai angka berupa data serial akan dikonversi menjadi instruksi untuk mengoperasiakan TV.

Hasil konversi data serial dari pengolahan citra diolah menjadi instruksi pengoperasian TV oleh mikrokontroler, selanjutnya mikrokontroler akan mengirimkan sinyal ke TV seperti : menghidupkan, mematikan, menaikkan chanel, menurunkan chanel, menaikkan volume dan menurunkan volume. Diagram sistem ditunjukkan pada Gambar 1.

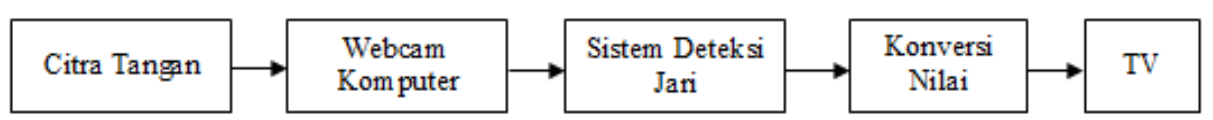

Gambar 1 Diagram Sistem Secara Keseluruhan

\subsubsection{Rancangan Program}

Pada program sistem deteksi jari terdapat beberapa subprogram yang merupakan proses-proses yang dilakukan sehingga bisa didapatkan jumlah jari. Diagram alir proses ini ditunjukkan pada Gambar 2.

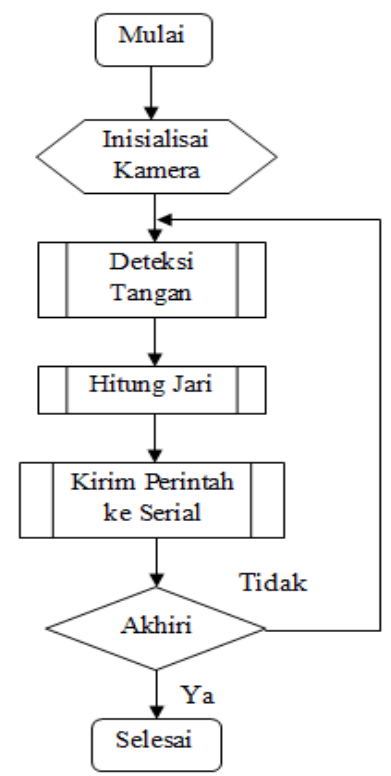

Gambar 2 Diagram Alir Program Deteksi Jari 
Hal pertama yang dilakukan adalah inisialisasi kamera untuk mengatasi ketika menemui keadaan kamera tidak ditemukan. Kemudian ketika kamera ditemukan dan dapat diaktifkan maka proses pengambilan citra akan berlangsung. Terdapat subprogram deteksi tangan, subprogram hitung jari dan subprogram hasil deteksi jari yang terhitung ke port serial.

\subsubsection{Subprogram Deteksi Tangan}

Deteksi tangan berfungsi untuk memisahkan antara citra tangan dengan latar belakang. Hal pertama yang dilakukan adalah merubah model warna pada citra menjadi HSV (Hue, Saturation, Value). Model warna HSV digunakan untuk mempermudah proses deteksi tangan berdasarkan dari rentang nilai minimum dan maksimum tiap komponen Hue, Saturation dan Valuenya dari warna kulit tangan. Setelah didapatkan citra tangan kemudian dilakukan pencarian garis luar tangan, sehingga didapatkan kontur tangan saja. Diagram alir subprogram deteksi tangan ditunjukkan pada Gambar 3.

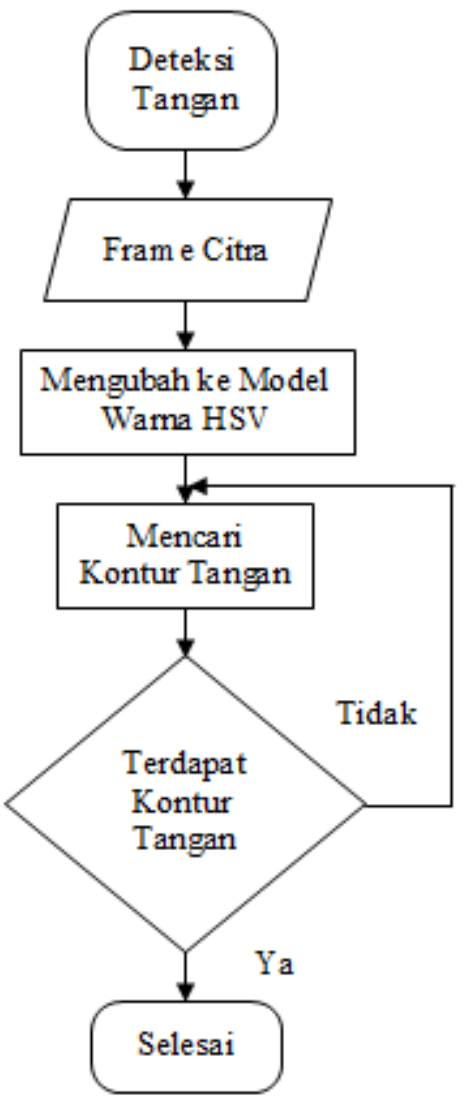

Gambar 3 Diagram Alir Subprogram Deteksi Tangan

\subsubsection{Subprogram Hitung Jari}

Pada subprogram hitung jari merupakan hasil dari subprogram deteksi tangan, yang didapatkan hasil berupa kontur tangan untuk diproses lebih lanjut. Proses yang dilalui adalah melakukan manipulasi terhadap kontur tangan sehingga didapatkan kontur jari saja, kemudian dilakukan penghitungan jumlah jari. Sehingga didapatkan nilai berupa angka pada tampilan layar monitor sesuai dengan jumlah jari yang ditangkap oleh kamera webcam. Diagram alir subprogram hitung jari ditunjukkan pada Gambar 4. 


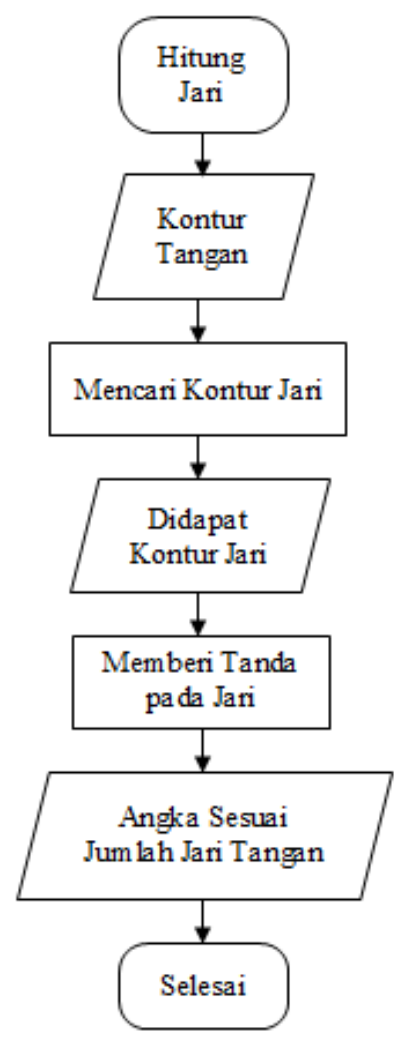

Gambar 4 Diagram Alir Subprogram Hitung Jari

\subsubsection{Subprogram Kirim Perintah ke Serial}

Program remote pada mikrokontroler bekerja menerima input data dari hasil pengolahan citra tangan dari komputer memanfaatkan komunikasi serial dan juga berfungsi sebagai konversi nilai pada data serial menjadi instruksi untuk pengoperasian TV. Masing-masing data yang diterima oleh mikrokontroler kemudian ditentukan masing-masing keluarannya. Data dan instruksi pengoperasian TV berdasarkan jari terdeteksi ditunjukkan pada Tabel 1.

Tabel 1 Jumlah Jari Terdeteksi dan Instruksinya

\begin{tabular}{|c|c|}
\hline Jumlah jari & Instruksi \\
\hline 5 & Volume Turun \\
\hline 4 & Volume Naik \\
\hline 3 & Chanel Turun \\
\hline 2 & Chanel Naik \\
\hline 1 & ON/OFF \\
\hline
\end{tabular}

Data yang dikirimkan oleh komputer melalui port serial, kemudian pada setiap data yang masuk dilakukan pembandingan antara data yang masuk dengan kode perintah yang sesuai. Jika yang diterima adalah data "1" maka akan diterjemahkan oleh mikrokontroler sebagai perintah untuk menghidupkan atau mematikan TV. Jika yang diterima adalah data "2" maka akan diterjemahkan oleh mikrokontroler sebagai perintah untuk menaikkan chanel TV. Jika yang diterima adalah data "3" maka akan diterjemahkan oleh mikrokontroler sebagai perintah untuk menurunkan chanel TV. Jika yang diterima adalah data "4" maka akan diterjemahkan oleh mikrokontroler sebagai perintah untuk menambahkan volume TV sedangkan jika yang diterima adalah data "5" maka akan diterjemahkan oleh mikrokontroler 
sebagai perintah untuk mengurangi volume TV. Data yang dikirimkan oleh komputer tersebut berdasarkan hasil jumlah jari yang terdeteksi. Diagram alir subprogram kirim perintah ke serial ditunjukkan pada Gambar 5.

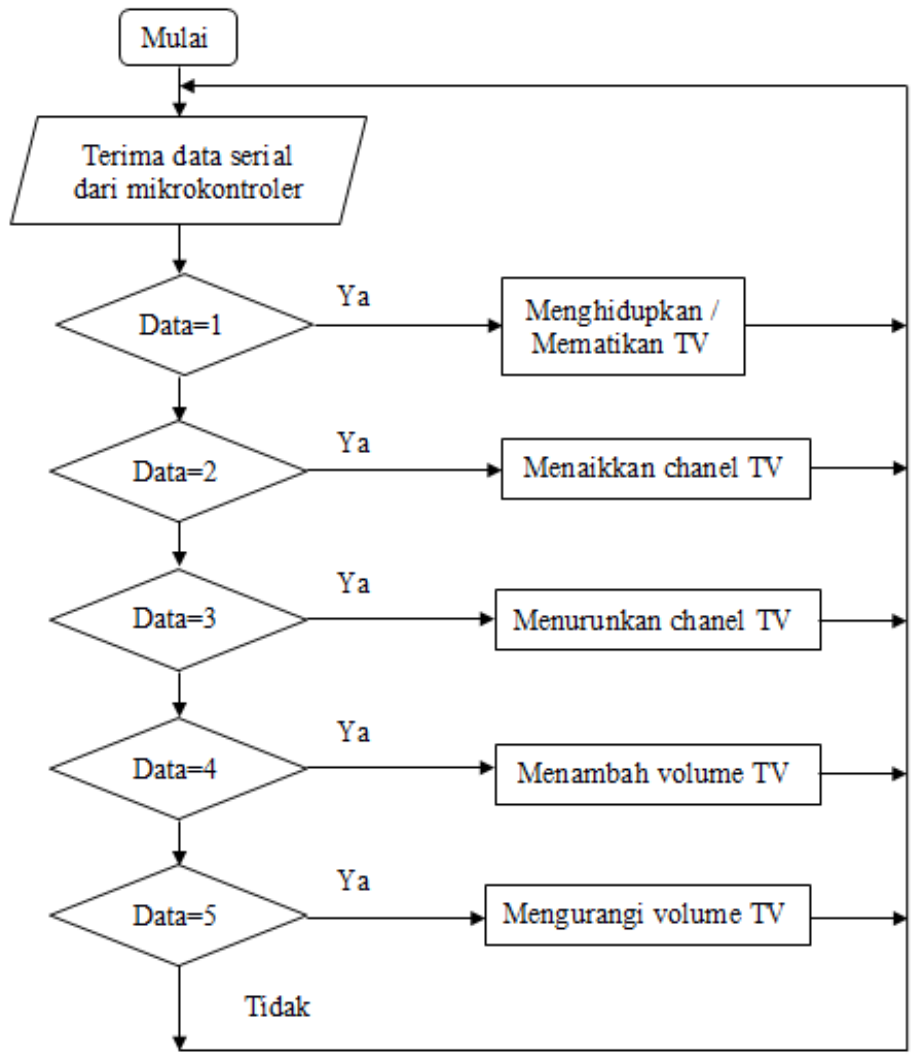

Gambar 5 Diagram Alir Subprogram Kirim Perintah ke Serial

\subsubsection{Instruksi Konversi Nilai}

Pada instruksi konversi nilai, terdapat rangkaian mikrokontroler dan beberapa komponen elektronika, yaitu : LED IR dan TSOP 1238 [6,7]. Mikrokontroler berfungsi menerima data serial dari hasil pemrosesan citra tangan dan berfungsi sebagai konversi nilai data serial menjadi instruksi yang dapat mengoperasikan TV. Led IR berfungsi mengirimkan sinyal ke TV. TSOP 1238 berfungsi menerima setiap kode pada remote yang telah ditentukan pada penelitian ini [8]. Sehingga TSOP 1238 dapat mengetahui kode untuk perintah pengoperasian TV dan led IR mengirimkan sinyal kode perintah tersebut ke TV, sehingga TV dapat dioperasikan dengan isyarat jari. Agar TSOP 1238 dapat membaca dan menerima setiap kode saat remote ditekan. Maka harus mendownload pustaka IRremote dan selanjutnya menjalankan program IRrecvdump untuk tahap pembacaan kode pada remote TV. Hasilnya setelah program IRrecvdump dijalankan maka setiap tombol remote yang ditekan, TSOP 1238 akan mendapatkan kode remote yang ditampilkan pada serial monitor mikrokontroler.

\section{HASIL DAN PEMBAHASAN}

Pada pendeteksian citra tangan ini menggunakan pustaka cv, highgui, cxcore, ml $[9,10,11]$. Untuk image processing dan vision menggunakan pustaka cv. Untuk pembuatan GUI, image dan video I/O menggunakan library highgui. Untuk struktur data, support XML dan fungsi-fungsi grafis menggunakan library cxcore. Sedangkan untuk clustering, klasifikasi data, fungsi analisis data dan untuk machine learning pustaka menggunakan pustaka ml. 


\subsection{Pengujian Sistem}

Langkah-langkah yang perlu dilakukan untuk melakukan pengujian deteksi jumlah jari untuk mengoperasikan TV, adalah sebagai berikut:

1. Arduino dipasang dan dihubungkan ke laptop dengan USB.

2. Program remote pada arduino dijalankan dengan mengklik "upload"seperti Gambar 6a.

3. Pada codeblock, program deteksi jari tangan dijalankan dengan mengklik "run" seperti Gambar 6b.

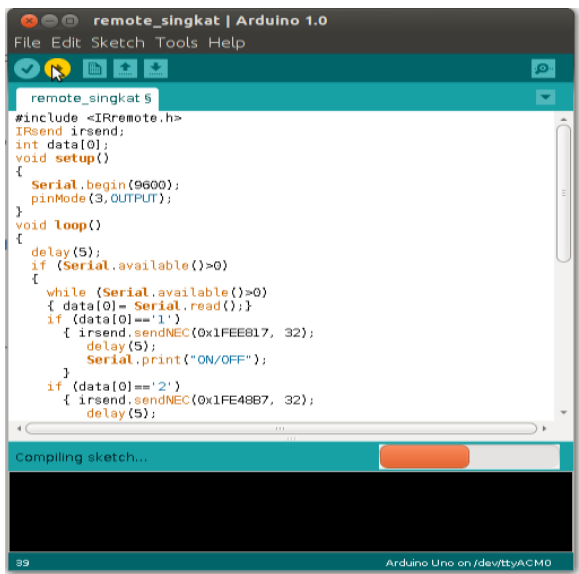

(a)

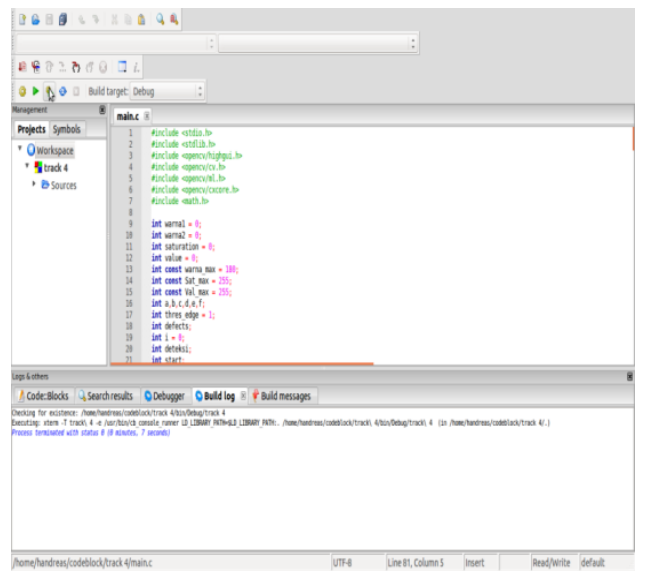

(b)

Gambar 6 (a) Tampilan Program Remote Arduino (b) Tampilan Awal Program Deteksi Jari Tangan

4. Akan muncul 4 jedela yaitu: Camera, HSV, Tepi dan Deteksi, seperti pada Gambar 7a.

5. Akan muncul jendela bernama "Deteksi" seperti Gambar 7b yang menampilakan trackbar guna memproses citra tangan. Yaitu dengan cara menggeser trackbar yang ada pada jendela "Deteksi" sehingga didapatkan hasil yang paling bagus.

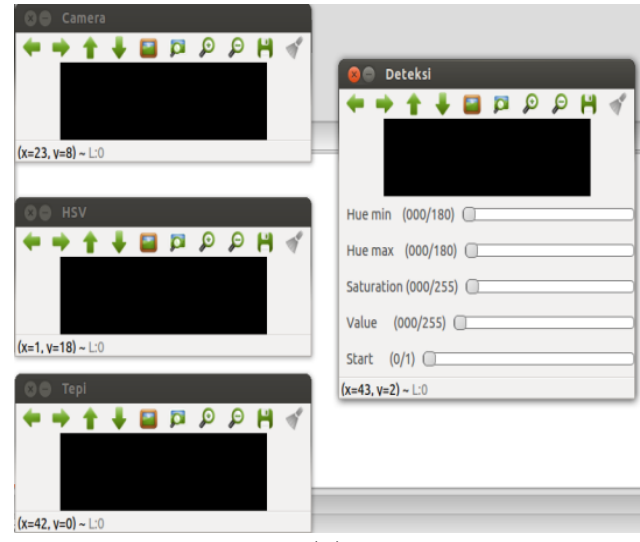

(a)

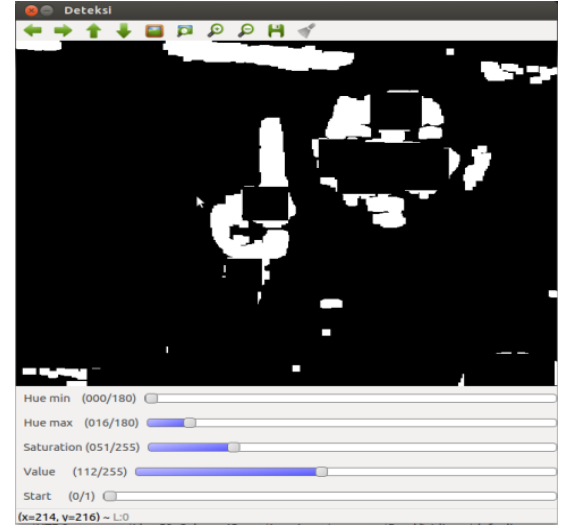

(b)

Gambar 7 (a) Tampilan 4 jendela (b) Tampilan Trackbar "Deteksi"

6. Tombol start pada trackbar nilainya harus diganti dengan nilai 1 supaya program pendeteksian jari tangan bisa berjalan dan dapat mengoperasikan TV. Seperti pada Gambar 8a, tombol start dibuat supaya sewaktu mengkalibrasi citra berupa jari tangan, nilai yang terdeteksi tidak dapat mengirimkan perintah serial ke arduino sebelum mengganti nilai start dengan nilai 1. 
7. Hasil dari pendeteksian jari tangan, pada jendela "Camera" akan muncul angka sesuai dengan jumlah jari yang tertangkap olek kamera laptop, seperti pada Gambar 8 b.

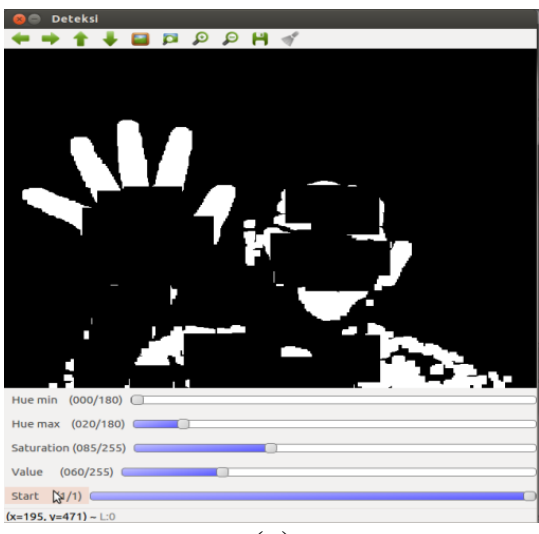

(a)

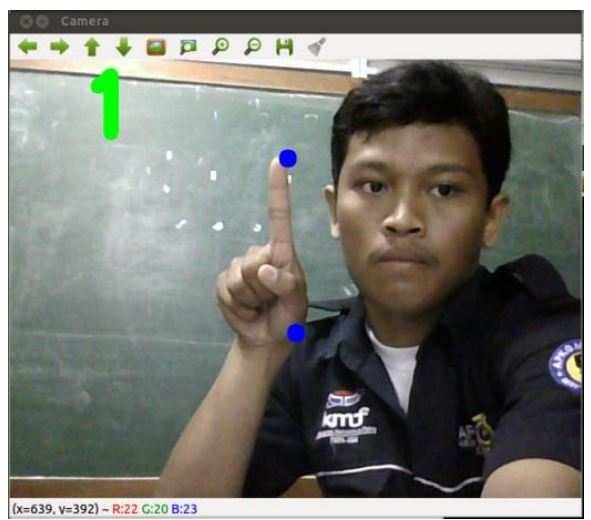

(b)

Gambar 8 (a) Tampilan "start" Mulai (b) Tampilan Nilai pada Jendela "Camera"

\subsection{Pengujian Pengaruh Intensitas Cahaya terhadap Jarak}

\subsubsection{Pengaruh Intensitas pada Jarak 20-40 cm dengan cahaya lampu}

Dalam pengolahan citra, intensitas cahaya dan jarak sangat mempengaruhi hasil citra yang ditangkap oleh kamera. Pengujian dilakukan di dalam ruangan Laboratorium Elektronika dan Instrumentasi (Lab. ELINS) pada pukul 07.00 s.d 12.00 dengan keadaan terdapat cahaya lampu dan tanpa lampu. Untuk pengujian tanpa adanya lampu bukan berarti tidak ada cahaya sama sekali, tetapi tetap mendapat cahaya dari sinar matahari yang masuk ke ruangan. Untuk pengujian jarak, dilakukan pengujian mulai jarak antara 20-120 cm. Pembagian jarak untuk pengujian yaitu: antara $20-40 \mathrm{~cm}, 50-80 \mathrm{~cm}$ dan $90-120 \mathrm{~cm}$. Hasil dari pengujian ditampilkan pada Tabel 2.

Tabel 2 Hasil Pengaruh Intensitas pada Jarak 20-40 cm dengan lampu

\begin{tabular}{|c|c|c|c|}
\hline $\begin{array}{c}\text { Intensitas } \\
\text { (lux) }\end{array}$ & Jumlah Jari & $\begin{array}{c}\text { Tampilan } \\
\text { Nilai }\end{array}$ & Keterangan \\
\hline \multirow{4}{*}{99} & 5 & 5 & volume turun \\
\cline { 2 - 4 } & 4 & 5 & volume turun \\
\cline { 2 - 4 } & 3 & 3 & chanel turun \\
\cline { 2 - 4 } & 2 & 2 & chanel naik \\
\hline \multirow{4}{*}{22} & 1 & 1 & on/off \\
\cline { 2 - 4 } & 5 & 5 & volume turun \\
\cline { 2 - 4 } & 4 & 4 & volume naik \\
\cline { 2 - 4 } & 3 & 3 & chanel turun \\
\cline { 2 - 4 } & 2 & 2 & chanel naik \\
\hline \multirow{4}{*}{95} & 1 & 2 & chanel naik \\
\cline { 2 - 4 } & 5 & 4 & volume naik \\
\cline { 2 - 4 } & 4 & 3 & chanel turun \\
\cline { 2 - 4 } & 2 & 3 & chanel turun \\
\cline { 2 - 4 } & 1 & 2 & chanel naik \\
\hline 89 & $1-5$ & tidak stabil & tidak akurat \\
\hline
\end{tabular}

Ketika tangan pengguna berada pada jarak $20 \mathrm{~cm}$ dengan intensitas 89 lux kamera dapat mengambil citra tangan pengguna tetapi mendapatkan hasil yang tidak stabil. Hal ini 
ditunjukkan dengan jari tangan tidak dapat dihitung dengan baik. Intensitas 89 lux pada jarak 20 $\mathrm{cm}$ terjadi pada background warna coklat. Sehingga hasil perhitungan jari menunjukkan nilai yang tidak stabil dan berubah-ubah. Hal ini dikarenakan proses deteksi jari tangan tidak berjalan dengan baik dan warna background coklat pada lemari yang menyerupai warna kulit pada manusia. Sehingga ketika dilakukan pengambilan citra jari tangan, warna coklat pada background mempengaruhi ketepatan dalam pengambilan citra jari tangan yang akan dideteksi. Akibatnya hasil yang didapatkan dalam pengambilan citra jari tangan tidak stabil dan nilainya selalu berubah-ubah.

\subsubsection{Pengaruh Background pada Jarak 50-80 cm tanpa lampu}

Pengujian terhadap background perlu dilakukan karena perlu diketahui apakah input berupa jari tangan tetap dapat dideteksi oleh kamera sebagai isyarat atau tidak. Background pada pengujian ini menggunakan warna-warna disekitar ruangan. Diantaranya : warna putih pada whiteboard, warna biru pada korden, warna hijau pada papan tulis dan warna coklat pada lemari. Dalam pengolahan citra, background dan jarak sangat mempengaruhi hasil citra jari tangan yang dicapture oleh kamera. Pengujian dilakukan di dalam ruangan dengan keadaan terdapat lampu sebagai pencahayaan dan tanpa lampu. Hasil pengujian ditampilkan dalam tabel dengan memvariasikan background, yaitu background putih, background biru, background coklat dan background hijau. Rentang jarak pada pengujian ini antara $20-40 \mathrm{~cm}, 50-80 \mathrm{~cm}$ dan 90-120 cm. Pada tabel juga membandingkan jumlah jari sebagai input yaitu satu jari, dua jari, tiga jari, empat jari dan lima jari dengan hasil citra jari tangan yang dapat ditangkap oleh kamera dan menampilkan keterangan dalam pengoperasian TV. Hasil pengujian dengan keadaan tanpa cahaya lampu di Laboratorium Elektronika dan Instrumentasi. Hasil pengujian ditunjukkan pada Tabel 3.

Tabel 3 Hasil Pengaruh Background pada Jarak 50-80 cm tanpa lampu

\begin{tabular}{|c|c|c|c|}
\hline Background & Jumlah Jari & Tampilan Nilai & Keterangan \\
\hline Putih & 5 & 5 & volume turun \\
\cline { 2 - 4 } & 4 & 4 & volume naik \\
\cline { 2 - 4 } & 3 & 3 & chanel turun \\
\cline { 2 - 4 } & 2 & 2 & chanel naik \\
\hline \multirow{6}{*}{ Biru } & 1 & 1 & on/off \\
\cline { 2 - 4 } & 5 & 5 & volume turun \\
\cline { 2 - 4 } & 4 & 4 & volume naik \\
\cline { 2 - 4 } & 3 & 3 & chanel turun \\
\hline Hijau & 2 & 2 & chanel naik \\
\cline { 2 - 4 } & 5 & 2 & volume turun \\
\cline { 2 - 4 } & 4 & 5 & chanel turun \\
\cline { 2 - 4 } & 3 & 3 & chanel naik \\
\cline { 2 - 4 } & 2 & 2 & tidak akurat \\
\hline Coklat & 1 & 1 & \\
\hline
\end{tabular}

Pada pengujian background warna putih dan warna hijau didapatkan hasil yang sesuai dengan input yang berupa jumlah jari. Sehingga pada jarak antara 50 sampai $80 \mathrm{~cm}$ pada background warna putih dan background warna hijau didapatkan hasil yang sesuai dengan penangkapan citra berupa jari tangan oleh kamera. Sedangkan pada background warna biru hampir semua nilai sesuai dengan pengambilan citra jari tangan yang dilakukan oleh kamera. Tetapi untuk jumlah jari 1 sebagai input yang akan ditangkap oleh kamera, menghasilkan nilai 2. Sedangkan pada background warna coklat menghasilkan nilai yang tidak stabil, dikarenakan warna coklat pada background mempengaruhi pengambilan citra jari tangan oleh kamera. 
Warna background coklat memiliki warna yang sama dengan warna kulit manusia sehingga mengakibatkan ketidakakuratan kamera dalam pengambilan citra jari tangan oleh kamera.

\subsubsection{Pengaruh Jarak terhadap Intensitas Cahaya \pm 5 lux}

Dalam pengolahan citra, jarak dan intensitas cahaya sangat mempengaruhi hasil citra yang dicapture oleh kamera. Sehingga diketahui seberapa batas maksimum dan minimum jarak jari tangan yang masih bisa dideteksi sebagai masukan. Pengujian dilakukan di dalam ruangan dengan keadaan tanpa lampu karena nilai intensitasnya lebih stabil. Intensitas cahaya yang diuji adalah \pm 5 lux, \pm 12 lux, $\pm 4,8$ lux dan $\pm 6,8$ lux. Hasil pengujian dengan keadaan tanpa cahaya lampu di Laboratorium Elektronika dan Instrumentasi. Hasil pengujian ditunjukkan pada Tabel 4.

Tabel 4 Hasil Pengaruh Jarak terhadap Intensitas Cahaya \pm 5 lux

\begin{tabular}{|c|c|c|c|}
\hline Jarak (cm) & Jumlah Jari & Tampilan Nilai & Keterangan \\
\hline \multirow{3}{*}{$20-40$} & 5 & 5 & volume turun \\
\cline { 2 - 4 } & 4 & 5 & volume turun \\
\cline { 2 - 4 } & 3 & 3 & chanel turun \\
\cline { 2 - 4 } & 2 & 3 & chanel turun \\
\hline $50-80$ & 1 & 1 & on/off \\
\cline { 2 - 4 } & 5 & 5 & volume turun \\
\cline { 2 - 4 } & 4 & 4 & volume naik \\
\cline { 2 - 4 } & 3 & 3 & chanel turun \\
\cline { 2 - 4 } & 2 & 2 & chanel naik \\
\hline $90-120$ & 1 & 1 & on/off \\
\cline { 2 - 4 } & 5 & 4 & volume naik \\
\cline { 2 - 4 } & 4 & 3 & chanel turun \\
\cline { 2 - 4 } & 2 & 2 & on/off \\
\cline { 2 - 4 } & 1 & tidak terdeteksi & tidak ada perintah \\
\hline
\end{tabular}

Pada pengujian jarak terhadap intensitas cahaya \pm 5 lux, pada jarak antara 50-80 cm memiliki nilai yang akurat antara input berupa citra jari tangan dengan hasilnya. Pada jarak antara 50-80 $\mathrm{cm}$ merupakan jarak yang akurat kamera dalam pengambilan citra pada intensitas cahaya \pm 5 lux. Sedangkan pada jarak $20-40 \mathrm{~cm}$ dan $90-120 \mathrm{~cm}$ hasil yang didapatkan dari pengambilan citra jari tangan oleh kamera, memiliki hasil yang tidak sesuai dengan input jumlah jari tangan. Hal ini disebabkan pengaruh jarak yang terlalu dekat antara tangan dengan kamera pada jarak 20-40 cm dan pengaruh jarak yang terlalu jauh antara tangan dengan kamera pada jarak $90-120 \mathrm{~cm}$.

\subsubsection{Pengujian Dilakukan di Rumah}

Pengujian yang dilakukan di rumah merupakan pengujian dengan jarak terbaik yaitu 70 $\mathrm{cm}$, intensitas cahaya sebesar 12 lux dan dengan latar belakang tembok warna biru. Intensitas cahaya pada ruangan selalu bernilai 12 lux yang dipengaruhi oleh cahaya lampu. Sehingga pada pengujian didapatkan nilai intensitas cahaya yang sama pada beberapa waktu pengujian. Pengujian dilakukan sebanyak 5 kali pada pagi, siang dan malam hari selama 2 hari (12 Desember-13 Desember 2013). Hasil pengujian yang dilakukan di rumah, ditunjukkan pada Tabel 5. 
Tabel 5 Hasil Pengujian Terbaik

\begin{tabular}{|c|c|c|c|c|}
\hline $\begin{array}{l}\text { Waktu } \\
\text { (WIB) }\end{array}$ & $\begin{array}{c}\text { Jumlah } \\
\text { Percobaan }\end{array}$ & Jumlah Jari & $\begin{array}{c}\text { Tampilan } \\
\text { Nilai }\end{array}$ & Keterangan \\
\hline \multirow[t]{5}{*}{9.30} & \multirow[t]{5}{*}{$5 x$} & 5 & 5 & volume turun \\
\hline & & 4 & 4 & volume naik \\
\hline & & 3 & 3 & chanel turun \\
\hline & & 2 & 2 & chanel naik \\
\hline & & 1 & 1 & on/off \\
\hline \multirow[t]{5}{*}{13.00} & \multirow[t]{5}{*}{$5 x$} & 5 & 5 & volume turun \\
\hline & & 4 & 4 & volume naik \\
\hline & & 3 & 3 & chanel turun \\
\hline & & 2 & 2 & chanel naik \\
\hline & & 1 & 1 & on/off \\
\hline \multirow[t]{5}{*}{18.30} & \multirow[t]{5}{*}{$5 x$} & 5 & 5 & volume turun \\
\hline & & 4 & 4 & volume naik \\
\hline & & 3 & 3 & chanel turun \\
\hline & & 2 & 2 & chanel naik \\
\hline & & 1 & 1 & on/off \\
\hline
\end{tabular}

Hasil dari tabel pengujian diatas adalah dengan intensitas sebesar 12 lux, jarak $70 \mathrm{~cm}$ dan latar belakang biru dihasilkan tampilan nilai yang baik, yaitu nilai yang ditunjukkan pada laptop sama seperti jumlah jari pengguna TV yang tertangkap oleh kamera. Akibatnya pengoperasian TV menjadi stabil dan akurat.

\section{KESIMPULAN}

Berdasarkan implementasi dan pengujian yang telah dilakukan dalam penelitian didapat beberapa kesimpulan sebagai berikut:

1. Citra tangan sebagai input dapat terdeteksi pada kondisi yang terbaik dan masih terdapat kendala.

2. Metode yang diterapkan untuk mengenali objek dengan memilah warna dengan latar belakangnya sudah berjalan dengan baik.

3. Hasil penelititan didapatkan kondisi yang terbaik yaitu: untuk intensitas cahaya terbaik dalam pengujian sebesar 12 lux, jarak tangan terhadap webcam yang terbaik adalah 70 $\mathrm{cm}$ dan background terbaik dalam pengujian berwarna biru.

\section{SARAN}

Untuk pengembangan dan penelitian lebih lanjut dari purwarupa yang telah dibuat saat ini, disarankan untuk membuat input lebih banyak lagi dikarenakan sementara ini baru menggunakan 5 input saja. Untuk pendeteksian ujung jari dibuat lebih sempurna, sehingga masukan citra berupa ujung jari bisa lebih stabil. 


\section{DAFTAR PUSTAKA}

[1] Gunanto, S. G., 2009. Segmentasi Bagian Warna Tubuh Manusia pada Citra 2D. Proceeding SENTIA.

[2] Oliviera, V. A., 2009, Skin Detection using HSV Color Space, http://www.matmidia.mat.puc-rio.br/sibgrapi/media/posters/59928.pdf, diakses pada tanggal 20 Februari 2013.

[3] Ho, L., 2011, Finger Detection and Gesture Recognition, http://www.code.google.com/p/finger-detection-and-gesture-recognition/, diakses pada tanggal 15 Februari 2013.

[4] Agarwal, K., 2012, Final Project Snap, http://www.golancourses.net/kaushal-agarwalfinal-project-snap/, diakses pada tanggal 18 Februari 2012.

[5] Hilmi, M.A., 2012, Purwarupa Kendali Lengan Dental Light dengan Isyarat Jari Berbasis Pengolahan Citra Digital (OPENCV), Skripsi, Elektronika dan Imnstrumentasi FMIPA UGM, Yogyakarta.

[6] Roysoala, 2013, IR Remote Menggunakan Arduino, http://www.roysoala.wordpress.com/ir-remote-menggunakan-arduino/, diakses pada 11 Agustus 2013.

[7] Shirriff, K., 2012, Multi Protocol Infrared Remote Library for The Arduino, http://www.arcfn.com/multi-protocol-infrared-remote-library.html/, diakses pada 5 Agustus 2013.

[8] Shirriff, K., 2012, Arduino IRremote, http://www.github.com/shirriff/ArduinoIRremotel, diakses pada 5 Agustus 2013.

[9] Chen, L., 2010, Fast Object Tracking using The OpenCV Library, http://www.lirtex.com/robotics/fast-object-tracking-robot-computer-vision/, diakses pada 7 Maret 2013.

[10] Fernando, S., 2010, Object Detection using Color Separation, http://www.opencvsrf.blogspot.com/object-detection-using-color-seperation.html/, diakses pada 12 April 2013.

[11 ]Burke, E., 2011, Finger Tracking Counting using OpenCV Convexity Defect, http://www.codeproject.com/Finger-tracking-counting-using-openCV-convexitydefect/, diakses pada 10 Mei 2013. 